\title{
Lies, damned lies, and statistics
}

\author{
Paul Kurlansky, MD
}

See related article on pages 14-9.

If your experiment needs a statistician, you need a better experiment.

—Ernest Rutherford

Recent query of PubMed with the term "propensity score matching" yielded 2458 responses, most of which were from the past 3 years (Figure 1). Introduced by Rosenbaum and Rubin ${ }^{1}$ in 1983 within the context of equating groups in cohort studies, the technique of propensity score matching languished in relative obscurity for decades. The classic 1999 publication in this Journal by Blackstone and colleagues $^{2}$ of "Two Internal Thoracic Artery Grafts Are Better Than One" not only transformed our understanding of arterial grafting but inaugurated a new era in our analytic approach to retrospective data.

Although often considered the criterion standard for evidence-based medicine, the prospective, randomized, controlled trial presents several challenges in studying surgical patients. Surgical procedures, unlike medications, which have a clear and uniform chemically determined composition, are nuanced and variable. Subtleties of technique, both surgeon and patient related, make multicenter trials and evaluation of outcomes challenging. Modification of technique and improvements in patient care make interpretation of historical data and optimal timing of study problematic. Moreover, equipoise is frequently difficult to achieve, especially among those most accomplished with a given procedure, resulting in potentially severe selection bias in patient recruitment and entry.

Challenges aside, the randomized, controlled trial selects patients at the point of study entry, whereas in retrospective studies patient selection has already occurred before study inception. The benefit of the former is the theoretic elimination of systematic bias, with the chance balancing of both recognized and unrecognized variables. The drawback is

From the Department of Surgery, Columbia University, New York, NY.

Disclosures: Author has nothing to disclose with regard to commercial support.

Received for publication March 27, 2015; accepted for publication March 28, 2015; available ahead of print April 22, 2015.

Address for reprints: Paul Kurlansky, MD, Department of Surgery, Columbia University, Black Building 210, 650 W 168th St, New York, NY 10032 (E-mail: pk2245@cumc.columbia.edu).

J Thorac Cardiovasc Surg 2015;150:20-1

$0022-5223 / \$ 36.00$

Copyright (c) 2015 by The American Association for Thoracic Surgery

http://dx.doi.org/10.1016/j.jtcvs.2015.03.051

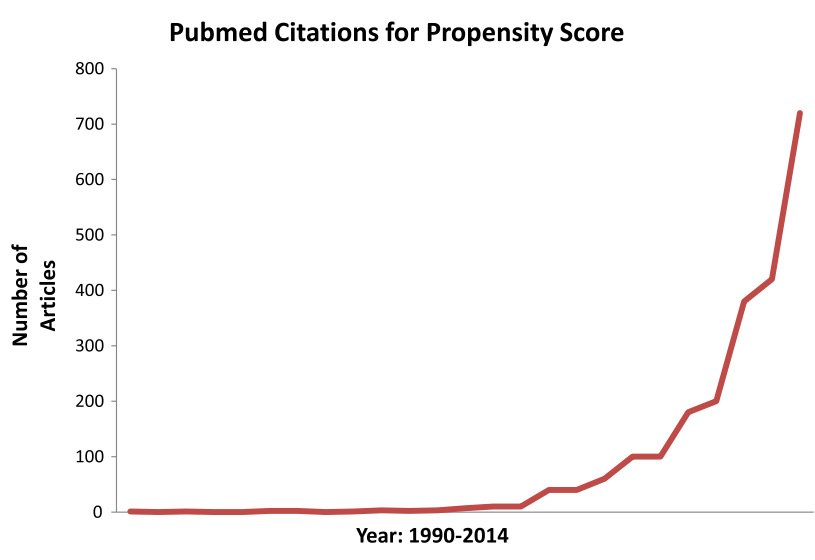

FIGURE 1. Number of article citations listed in PubMed in response the query "propensity score matching" during the period from 1990 through 2014.

that patient selection may introduce a design bias, with a study group that may not be representative of the actual clinical population of interest. For example, between 3\% and $8 \%$ of patients screened for inclusion in randomized trials comparing coronary artery bypass grafting with percutaneous coronary intervention have actually been in enrolled in these trials ${ }^{3-6}$ - excellent internal validity, but potentially limited external validity. It is just this opportunity that review of large clinical databases and registries potentially addresses-what information can we glean from the "real world" practice of medicine to inform clinical practice? Enter the propensity score methodology. As nicely explained by McMurry and colleagues $^{7}$ in their article in this issue of the Journal, when properly applied this technique permits the careful balancing of recognized variables and thus facilitates comparison of outcomes between clinically comparable groups of patients. As with any approach, there are pitfalls. Selection of variables needs to reflect the determinants of group membership and ideally should be predictive of outcome. The impact of unrecognized variables, however, cannot be overlooked-issues related to frailty, socioeconomic status, psychic state, health care attitudes, and goals can all have a profound impact on the results of surgical interventions, and yet such variables are rarely accounted for in clinical or administrative databases. Depending on the degree of difference between the groups being compared, the patients whom one is able to match may be relatively few and therefore not actually reflective of the group that they are presumed to represent. If one applies propensity scores to generate comparative quintiles of probability, the groups may well be unbalanced numerically, and the sample size is essentially divided by 
5, limiting statistical power. If, on the other hand, one uses propensity scoring to generate matched groups, there is the risk of losing potentially valuable information that might be gleaned from the unmatched patients. The use of a propensity score to adjust regression may not maximize information regarding patient selection. There are a variety of valid matching techniques, indicative of the imperfect science of balancing competing criteria, of match closeness, estimates of variance, and the numbers of subjects included and excluded. ${ }^{8}$ The most appropriate techniques for analysis are controversial, depending on whether one views the resulting groups as matched or independent. ${ }^{9,10}$ Regardless of which analytic technique one advocates, however, it appears that there is a general consensus that there is a disturbing prevalence of statistical shortcomings in the application of this technique, both in the medical literature in general ${ }^{7}$ and in the cardiovascular literature in particular. ${ }^{711}$ Thus the careful advice offered by McMurray and colleagues ${ }^{7}$ provides a most welcome guide for both investigators and readers.

The truly "definitive" study has never been-nor will it ever be-performed. Each investigation is limited by the information available and the analytic approaches that are most appropriate. The more careful one is in applying methodology, the more likely to be meaningful are the findings. No single study or approach, however, no matter how rigorously applied, can complete the picture. It is only through careful examination of multiple studies, both prospective and retrospective, both focused and broad, both clinical and scientific, that the truth begins to emerge.

\section{References}

1. Rosenbaum PR, Rubin DB. The central role of the propensity score in observational studies for causal effects. Biometrika. 1983;70:41-55.

2. Lytle BW, Blackstone EH, Loop FD, Houghtaling PL, Arnold JH, Akhrass R, et al. Two internal thoracic artery grafts are better than one. J Thorac Cardiovasc Surg. 1999;117:855-72.

3. King SB III, Lembo NJ, Weintraub WS, Kosinski AS, Barnhart HX, Kutner MH, et al. A randomized trial comparing coronary angioplasty with coronary bypass surgery. Emory Angioplasty versus Surgery Trial (EAST). N Engl J Med. 1994; 331:1044-50.

4. Coronary angioplasty versus coronary artery bypass surgery: the Randomized Intervention Treatment of Angina (RITA) trial. Lancet. 1993;341:573-80.

5. Rodriguez A, Bernardi V, Navia J, Baldi J, Grinfeld L, Martinez J, et al. Argentine randomized study: coronary angioplasty with stenting versus coronary bypass surgery in patients with multiple-vessel disease (ERACI II): 30-day and one-year follow-up results. ERACI II Investigators. J Am Coll Cardiol. 2001;37: $51-8$.

6. Farkouh ME, Domanski M, Sleeper LA, Siami FS, Dangas G, Mack M, et al; FREEDOM Trial Investigators. Strategies for multivessel revascularization in patients with diabetes. $N$ Engl J Med. 2012;367:2375-84.

7. McMurry TL, Hu Y, Blackstone EH, Kozower BD. Propensity scores: methods, considerations, and applications in the Journal of Thoracic and Cardiovascular Surgery. J Thorac Cardiovasc Surg. 2015;150:14-9.

8. Streiner DL, Norman GR. The pros and cons of propensity scores. Chest. 2012; 142:1380-2.

9. Austin PC. A critical appraisal of propensity-score matching in the medical literature between 1996 and 2003. Stat Med. 2008;27:2037-49.

10. Schafer JL, Kang J. Average causal effects from nonrandomized studies: a practical guide and simulated example. Psychol Methods. 2008;13:279-313.

11. Austin PC. Propensity-score matching in the cardiovascular surgery literature from 2004 to 2006: a systematic review and suggestions for improvement J Thorac Cardiovasc Surg. 2007;134:1128-35. 